\title{
Starch sources influence lipidaemia of diabetic dogs
}

\author{
Fabio Alves Teixeira', Daniela Pedrosa Machado', Juliana Toloi Jeremias², Mariana Ramos Queiroz', \\ Cristiana Ferreira Fonseca Pontieri ${ }^{2}$ and Marcio Antonio Brunetto ${ }^{1,3^{*}}$
}

\begin{abstract}
Background: Hyperlipidaemia is considered a cause of other diseases that are clinically important and potentially life threatening. Combination of pea and barley as exclusive starch sources is known to interfere with glycemic control in diabetic dogs, but their effect on lipid profile of hiperlipidaemic dogs is yet to be evaluated. Twelve adult diabetic dogs were fed three dry extruded diets with different starch sources and different fat levels: peas and barley (PB), maize (Mi), and peas, barley and rice (Ba) with 15.7, 15.6 and 9.0\% of their dry matter as fat, respectively. Plasmatic cholesterol and triglycerides concentration curves over $10 \mathrm{~h}$ were obtained after 60 days on each diet and with the same NPH insulin dose. ANOVA test or Friedman test were used to compare the dietary effects on triglycerides and cholesterol variables among the diets.

Results: Dogs presented lower mean $(p=0.05)$, fasting $(p=0.03)$, and time 8-h postprandial $(p=0.05)$ triglyceridemia after PB diet period than Ba diet period and time 4-h postprandial $(p=0.02)$ lower after PB than Mi diet. Cholesterolemia mean, minimum, maximum, area under the cholesterol curve and times points: 2, 4, 6, 8 and 10-h postprandial, had lower values after PB ingestion in comparison to Mi, without difference to Ba diet.
\end{abstract}

Conclusion: Inclusion of pea and barley, as exclusive starch sources, in therapeutic diets for diabetic dogs can minimize plasmatic triglycerides and cholesterol concentration at fasting and at different postprandial time, compared to the maize diet or diet with lesser fat content.

Keywords: Cholesterol, Triglycerides, Nutrition, Endocrinopathy

\section{Background}

Hyperlipidaemia refers to an increased concentration of lipids in the blood. It is associated with other canine diseases that are clinically important and potentially life threatening such as pancreatitis [1-3], gall bladder mucocele [4], atherosclerosis [5-9], ocular [10] and neurologic diseases $[11,12]$. Specifically about Miniature Schnauzers, hyperlipidemia was associated to hepatopathies [13], insulin resistance [14] and proteinuria $[15,16]$.

\footnotetext{
* Correspondence: mabrunetto@usp.br

This study was presented, in part, at the 2018 ACVIM Forum, June 14-16, 2018, Seattle, Washington.

'School of Veterinary Medicine and Animal Science, University of São Paulo,

São Paulo/Pirassununga, Av. Prof. Orlando Marques de Paiva, 87 - Butantã,

São Paulo 05508-010, Brazil

${ }^{3}$ Department of Animal Nutrition and Production, School of Veterinary

Medicine and Animal Science, São Paulo University, Av. Duque de Caxias

Norte, 255, Pirassununga, SP, Brazil

Full list of author information is available at the end of the article
}

Secondary hyperlipidaemia is the most common form of hyperlipidaemia in dogs [17], mainly resulting from an endocrine disorder [18-20], such as diabetes mellitus (DM). Thereupon, it has been recommended that diets for diabetic dogs must be moderate to low in fat [21], since it may minimize plasmatic lipid concentrations; and high fiber content since it may lead to a decrease in blood glucose levels [22-25]. However, there is evidence suggesting that the low-fat and high-fiber combination has side effects such as deficient weight gain, bulk and softened feces, flatulence, constipation, vomit, opaque hair and lesser palatability [21-26], probably due to the effect of dietary fiber on dog microbiota [27]. Therefore, new strategies should be investigated to improve diet design for diabetic dogs.

Starch source affect significantly the digestibility of the diet [28]; and interferes with the postprandial glycemic curves in diabetic dogs $[29,30]$. Previously, our group showed that pea and barley mix as exclusive dietetic 
starch minimize postprandial glycemia in diabetic dogs compared to maize [29]. But studies focusing on lipid profile of dogs with endocrinopathies feeding different starch sources were not found.

Thus, this study aims to assess the influence of two levels of dietary fat content, and two starch sources pea with barley vs maize - on the lipid profile of dogs with stable DM.

\section{Results}

After consumption of each diet for 2 months, and under the same insulin dosage; the lipid metabolism of diabetic dogs was evaluated by 10 -h plasmatic triglycerides (Fig. 1) and cholesterol (Fig. 2) concentration curves. Twelve animals were included in the analysis (Table 1). Patients ranged from 5 to 12 years of age with a mean of 8.3 years. No significant variation $(p=0.12)$ of body weight were observed at the end of each diet administration period (Table 1).

The means from the variables obtained from the triglycerides and cholesterol curves for each animal after each dietary treatment were compared (Table 2).

Regarding plasmatic triglycerides concentration, mean $(p=0.05)$, fasting ( $\mathrm{t} 0 ; p=0.03)$, and time 8 -h postprandial (t8; $p=0.05$ ) were lower after PB diet period than Ba diet. At time 4-h postprandial (t4; $p=0.02)$, PB diet resulted in lower plasmatic triglycerides levels than $\mathrm{Mi}$ diet (Table 2).

Cholesterol differed more than triglyceridemia concerning the two isonutrient diets. Only fasting (t0), difference between maximum and minimum, and AUICC presented no difference between diets periods (Table 2). All difference variables $(p \leq 0.05$; Table 2$)$ showed higher cholesterol concentrations after Mi diet period than PB diet, similar values between $\mathrm{PB}$ and $\mathrm{Ba}$ diet periods, and some variables ( $\mathrm{t} 2, \mathrm{t} 6, \mathrm{t} 8$, mean, maximum) did not differ between the Mi and Ba diet (Table 2).

\section{Discussion}

This clinical trial results showed a possible lipidlowering effect of $\mathrm{PB}$ diet. This influence of $\mathrm{PB}$ diet on plasmatic cholesterol and triglycerides concentrations could be attributed to the difference of dietary fat levels. Indeed, the only publication, to our knowledge, that evaluated the amount of dietetic fat for diabetic dogs, also showed a decrease in lipid profiles in response to lower dietary fat levels [21]. Although, in our study comparing $\mathrm{PB}$ and $\mathrm{Mi}$, they both had the same ethereal extract content (Table 3), so dietetic fat amount did not justify the lipid lowering effect of PB diet. Moreover, differently from Fleeman et al. [21], which studied diabetic dogs, and similar to healthy dog evaluated by Elliot et al. [31], our results showed more similarities in plasmatic lipid concentrations than differences among the lowest fat diet (9.0\% in dry matter basis) and the others diets (around 15.6\%). Probably, Fleeman et al. [21] observed significant influence of dietary fat content on plasmatic lipid concentration because they had a greater difference in the amount of dietary fat being compared (from 2.45 to $5.75 \mathrm{~g}$ of fat $/ 100 \mathrm{kcal}$ ) than this study $(2.78$ to $4.09 \mathrm{~g}$ of fat $/ 100 \mathrm{kcal}$ ) and that of Elliot et al. [31] [2.70 to 3.96 - values determined using modified Atwater factors [32] based on information of percentage of metabolizable energy from fat, expressed by authors]. Thus, we suggest that there are other factors involved in the hypolipidemic effect of the PB diet in our observations.

Regarding the ingredients, $\mathrm{PB}$ and Mi have the same fat sources with small differences in the amount

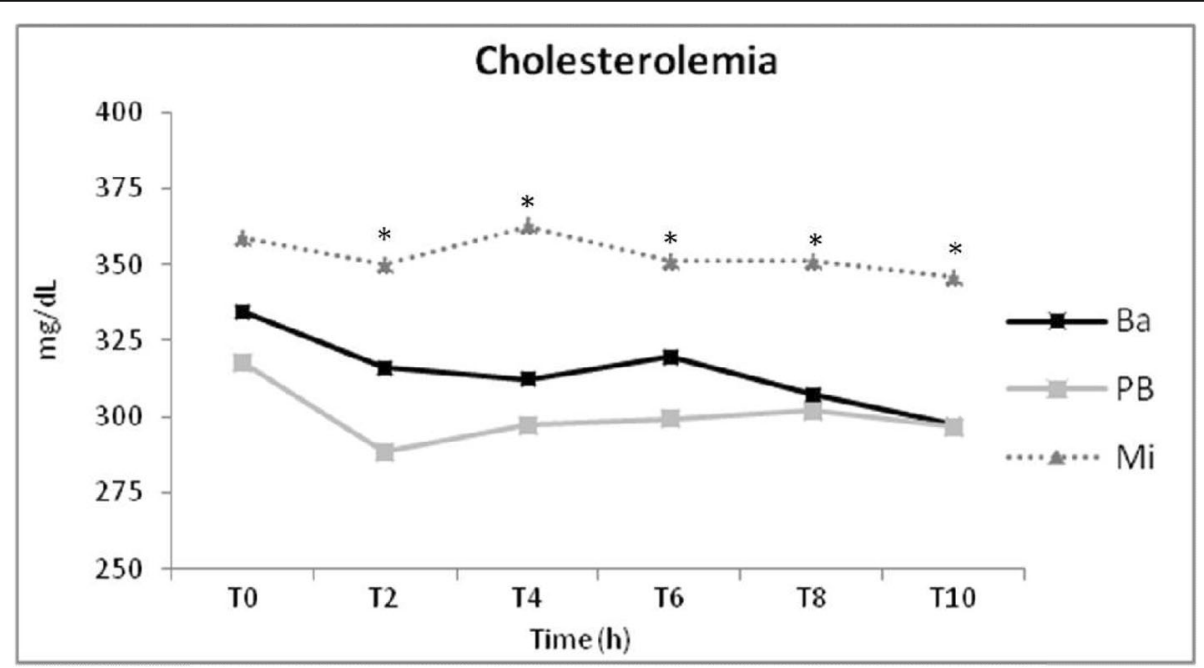

Fig. 1 Mean plasmatic triglycerides concentration of 12 diabetic dogs after 2 months feeding of basal (Ba), pea with barley (PB) and maize (Mi) diets. *Time with difference among diets 


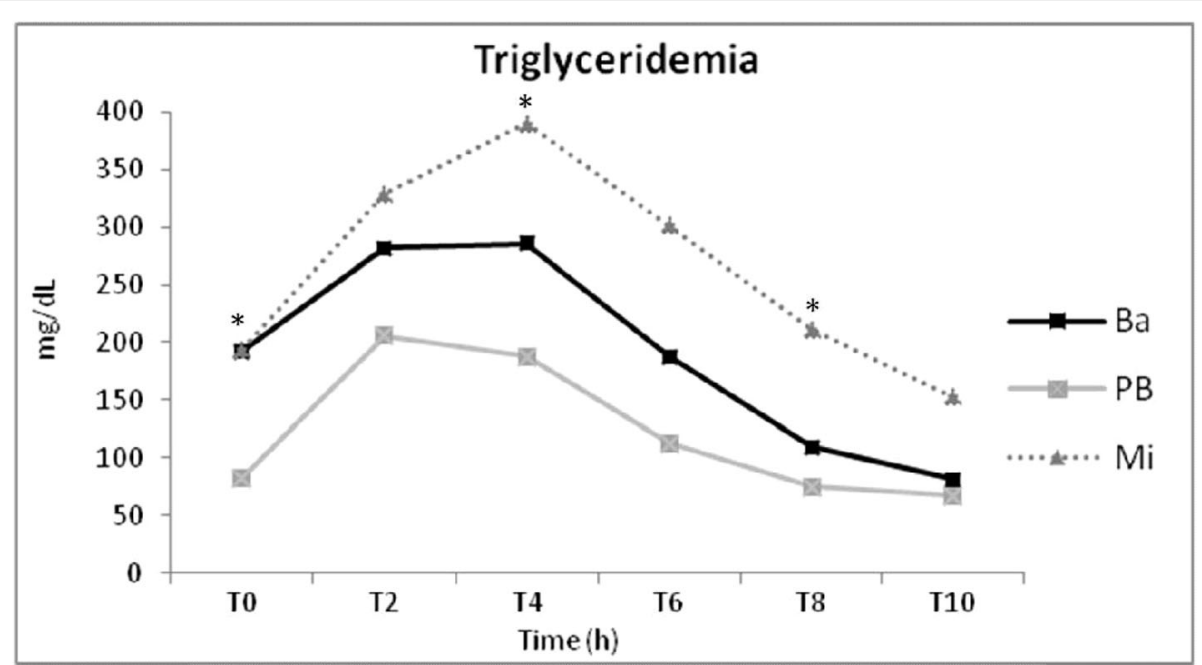

Fig. 2 Mean plasmatic triglycerides concentration of 12 diabetic dogs after 2 months feeding of basal (Ba), pea with barley (PB) and maize (Mi) diets. *Time with difference among diets

included. PB diet has the same percentage of fish oil and pork fat included, higher poultry fat $(6.0 \times 4.3 \%)$, and lower chicken by-product inclusion (24.0 X $32.0 \%)$ than Mi diet (Table 3). Considering that chicken by-product has around $14.0 \%$ fat, the inclusion of this ingredient in the $\mathrm{Mi}$ diet would not result in higher poultry fat amount than PB diet. Moreover, it has been shown that dietary fat source influences serum cholesterol concentrations in dogs, irrespective of dietary protein source [33]. Therefore, it was expected that PB would translate in higher cholesterolemia than $\mathrm{Mi}$ diet because of the greater poultry fat inclusion; however, fat source does not explain the lower plasmatic lipid concentration after the PB diet period.
In turn, dietary starch amounts could alter postprandial glucose response in healthy pets [34, 35] and lipid response in humans [36], but the three diets had close starch amounts.

A better explanation would be the possibility that peas and barley act as functional foods for diabetic dogs due to the possible presence of components that can minimize hyperlipidemia. An early study comparing the effects of peas or maize (corn flakes) addition in the feed of humans with different degrees of cholesterolemia, observed a decrease in the concentration of cholesterol after consumption of pea [37]. The authors speculated that higher consumption of pea fiber was the cause of these effects. Since it was more fermentable it would

Table 1 Characteristics of 12 diabetic dogs at the beginning of the study

\begin{tabular}{|c|c|c|c|c|c|c|c|c|}
\hline \multirow[t]{2}{*}{ Breed } & \multirow[t]{2}{*}{ Sex } & \multirow{2}{*}{$\begin{array}{l}\text { Age } \\
\text { (years) }\end{array}$} & \multicolumn{3}{|c|}{ Body weight $(\mathrm{kg})^{\mathrm{a}}$} & \multirow{2}{*}{$\begin{array}{l}\text { Body } \\
\text { condition } \\
\text { score }\end{array}$} & \multicolumn{2}{|c|}{ NPH insulin (unit/kg) } \\
\hline & & & Post-Ba & Post-PB & Post-Mi & & Morning & Night \\
\hline Mixed breed & Intact male & 7 & 10.5 & 10.4 & 10.0 & 4 & 0.67 & 0.67 \\
\hline Labrador retriever & Neutered male & 9 & 30.1 & 31.5 & 31.4 & 5 & 0.50 & 0.50 \\
\hline Mixed breed & Spayed female & 9 & 5.8 & 5.7 & 6.0 & 5 & 0.17 & 0.17 \\
\hline Cocker & Spayed female & 5 & 12.5 & 12.9 & 12.1 & 5 & 0.64 & 0.64 \\
\hline Mixed breed & Spayed female & 12 & 10.4 & 10.4 & 10.4 & 5 & 0.19 & 0.19 \\
\hline Labrador retriever & Spayed female & 8 & 29.5 & 30.3 & 30.4 & 5 & 0.34 & 0.34 \\
\hline Labrador retriever & Intact male & 7 & 45.5 & 45.0 & 45.6 & 5 & 0.40 & 0.40 \\
\hline Schnauzer & Neutered male & 7 & 8.9 & 8.5 & 8.5 & 4 & 0.68 & 0.68 \\
\hline Labrador retriever & Intact male & 7 & 38.0 & 38.6 & 38.0 & 5 & 0.39 & 0.39 \\
\hline Labrador retriever & Spayed female & 10 & 25.1 & 26.4 & 26.3 & 5 & 0.40 & 0.40 \\
\hline Pug & Spayed female & 9 & 9.5 & 10.0 & 10.0 & 6 & 0.85 & 0.85 \\
\hline Dachshund & Spayed female & 9 & 6.6 & 6.7 & 6.6 & 5 & 0.23 & 0.23 \\
\hline
\end{tabular}

${ }^{a}$ Without difference after each diet period ( $p=0.12$ obtained by ANOVA test) 
Table 2 Mean and standard deviation of plasmatic triglycerides and cholesterol concentration of 12 diabetic dogs after 2 months feeding of basal (Ba), pea with barley (PB) and maize (Mi) diets

\begin{tabular}{|c|c|c|c|c|c|c|c|c|c|c|c|c|c|c|}
\hline \multirow{2}{*}{$\begin{array}{l}\text { Variables } \\
\text { (mg/dL) }\end{array}$} & \multicolumn{7}{|c|}{ Triglycerides } & \multicolumn{7}{|c|}{ Cholesterol } \\
\hline & $\mathrm{Ba}$ & $\mathrm{sd}$ & PB & $\mathrm{Sd}$ & $\mathrm{Mi}$ & $\mathrm{sd}$ & $P$ & $\mathrm{Ba}$ & $\mathrm{sd}$ & PB & $\mathrm{sd}$ & $\mathrm{Mi}$ & $\mathrm{sd}$ & $P$ \\
\hline$\overline{\mathrm{TO}}$ & $192.4^{\dagger}$ & 238.8 & $83.8^{\ddagger}$ & 43.9 & $194.8^{\text {t† }}$ & 283.3 & $0.03^{* *}$ & 334.6 & 113.3 & 318.1 & 96.7 & 358.8 & 119.6 & $0.11^{*}$ \\
\hline $\mathrm{T} 2$ & 282.1 & 262.8 & 205.9 & 144.4 & 328.4 & 340.2 & $0.44^{* *}$ & $316.4^{\dagger, \neq}$ & 100.1 & $288.7^{\dagger}$ & 85.2 & $350.2^{\ddagger}$ & 113.9 & $0.02^{*}$ \\
\hline T4 & $285.9^{\dagger \neq}$ & 254.7 & $188.3^{\dagger}$ & 175.9 & $389.5^{\ddagger}$ & 392.9 & $0.02^{* *}$ & $312.5^{\dagger}$ & 106.0 & $297.2^{\dagger}$ & 101.4 & $362.7^{\ddagger}$ & 127.1 & $0.01^{*}$ \\
\hline T6 & 187.6 & 167.5 & 113.4 & 125.3 & 301.2 & 381.4 & $0.10^{* *}$ & $319.9^{\dagger \neq}$ & 106.3 & $299.5^{\dagger}$ & 102.5 & $351.2^{\ddagger}$ & 112.3 & $0.02^{*}$ \\
\hline T8 & $109.9^{\dagger}$ & 76.7 & $75.8^{\ddagger}$ & 46.6 & $211.6^{\dagger \neq}$ & 306.6 & $0.05^{* *}$ & $307.6^{\dagger \neq}$ & 123.8 & $302.1^{\dagger}$ & 91.6 & $351.0^{\ddagger}$ & 117.1 & $0.03^{*}$ \\
\hline $\mathrm{T} 10$ & 81.5 & 51.0 & 67.5 & 30.2 & 152.7 & 195.5 & $0.37^{* *}$ & $297.6^{\dagger}$ & 113.9 & $296.7^{\dagger}$ & 93.0 & $345.9^{\ddagger}$ & 115.3 & $0.02^{*}$ \\
\hline Mean & $189.9^{\dagger}$ & 161.9 & $120.6^{\ddagger}$ & 79.1 & $263.0^{\dagger \neq}$ & 309.9 & $0.05^{* *}$ & $314.8^{\dagger \neq}$ & 108.6 & $303.0^{\dagger}$ & 96.3 & $353.3^{\neq}$ & 116.6 & $0.02^{*}$ \\
\hline Minimum & 76.4 & 51.7 & 63.7 & 30.7 & 141.9 & 198.8 & $0.34^{* *}$ & $282.7^{\dagger}$ & 104.4 & $284.5^{\dagger}$ & 85.2 & $334.2^{\ddagger}$ & 108.5 & $<0.01^{*}$ \\
\hline Maximum & 316.8 & 260.4 & 221.7 & 180.5 & 397.8 & 386.3 & $0.10^{*}$ & $341.4^{\dagger \neq}$ & 116.5 & $323.9^{\dagger}$ & 102.7 & $376.2^{\ddagger}$ & 122.6 & $0.02^{*}$ \\
\hline$\Delta$ & 240.5 & 244.3 & 158.0 & 175.9 & 255.9 & 224.5 & $0.18^{*}$ & 58.7 & 37.6 & 39.4 & 22.9 & 42.0 & 24.2 & $0.18^{*}$ \\
\hline AUC & 2004.7 & 1692.0 & 1349.8 & 919.5 & 2809.0 & 3256.1 & $0.09^{* *}$ & $3145.2^{\dagger}$ & 1081.6 & $2856.0^{\dagger}$ & 819.9 & $3534.8^{\ddagger}$ & 1166.9 & $0.01^{*}$ \\
\hline AUIC & 81.1 & 925.4 & 509.7 & 582.6 & 861.2 & 1078.5 & $0.12^{*}$ & -201.2 & 238.3 & -183.0 & 141.9 & -52.8 & 175.7 & $0.20^{*}$ \\
\hline
\end{tabular}

sd Standard deviation, AUC Area under the curve, AUIC Area under the increment curve; $\Delta$, difference between maximum and minimum values

${ }^{+, \neq}$Different superscript symbols means statistically difference in line between diets $(p \leq 0.05)$

${ }^{*} P$ value obtained by ANOVA test (post-hoc Tukey test)

${ }^{* *} P$ value obtained by Friedman (post-hoc multiple comparisons test)

promote higher excretion of bile acids due to direct effect on transit time and the fiber's direct stimulation would increase the content of bile acids in the feces.

Furthermore, barley is known to contain an abundance of soluble and insoluble fiber. Studies in humans and rat models, show that barley's fiber content is the main feature associated to better lipid indexes, predominantly soluble fiber [38-41]. In our study, despite the similarity into the total dietary fiber content among the three diets used, the PB diet had a higher amount of soluble fiber, which could justify part of its positive effect on plasma lipid concentration. Indeed, previous studies with

Table 3 Chemical composition of basal (Ba), pea with barley (PB) and maize (Mi) diets

\begin{tabular}{llll}
\hline Item (\% dry matter) & $\mathrm{Ba}^{\mathrm{a}}$ & $\mathrm{PB}^{\mathrm{b}}$ & $\mathrm{Mi}^{\mathrm{c}}$ \\
\hline Crude protein & 39.5 & 37.2 & 34.7 \\
Ethereal extract (hydrolysis) & 9.0 & 15.7 & 15.6 \\
Total dietary fiber & 19.6 & 20.6 & 19.3 \\
Soluble fiber & 1.6 & 3.3 & 1.0 \\
Insoluble fiber & 18.0 & 17.3 & 19.3 \\
Ash & 6.3 & 6.3 & 5.6 \\
Starch & 19.1 & 19.7 & 21.4 \\
Metabolizable energy (kcal/g DM) & 3.2 & 3.8 & 3.9 \\
\hline
\end{tabular}

${ }^{a}$ chicken by-product meal, wheat gluten, swine isolate protein, pea flour, barley, brewer's rice, porcine plasma powder, dried egg, cellulose, beet pulp, poultry fat, fish oil, $\beta$-glucan, gelatin hydrolisate

${ }^{b}$ Pea flour, barley, chicken by-product meal (24.0\%), wheat gluten, pork fat $(2.0 \%)$, swine isolate protein, cellulose, beet pulp, poultry fat $(6.0 \%)$, fish oil ${ }^{\mathrm{C}}$ Maize, chicken by-product meal (32.0\%), wheat gluten, pork fat $(2.0 \%)$, swine isolate protein, cellulose, beet pulp, chicken fat (4.3\%), fish oil diabetic dogs showed lower fasting cholesterolemia after ingestion of insoluble high fiber diet [23] and undistinguished high fiber diet [22].

A systematic review [41] attributed the use of barley to significantly lower total cholesterol, low-density lipoprotein cholesterol and triglycerides in humans due to high content of $\beta$-glucan inherent to this ingredient. $\beta$-glucan is also associated to reduced gastric emptying, digestion, and absorption of cholesterol and fat, and increased excretion of bile acids, neutral sterols and catabolism of cholesterol $[38,39]$. Despite the lack of a direct analysis of dietary $\beta$-glucan content, the inclusion of $\beta$-glucan in the commercial Ba diet (Table 3) and the presence of barley at PB diet could explain some similarities in the results regarding triglyceridemia and cholesterolemia between these diets, as well as the differences to Mi diet.

Recent studies also showed that pea protein can result in decrease of blood triglycerides and cholesterol concentration in different species [37, 42-45]. Possible mechanisms of action are not fully clarified but researchers correlated the consumption of pea protein to high hepatic LDL-receptor mRNA concentration, consequently increasing hepatic LDL receptor leading to accelerated clearance of LDL-cholesterol particles [42]; along with lower fatty acid synthesis due to down regulation of hepatic mRNA concentrations of fatty acid synthase and stearoyl-CoA desaturase - fatty acids synthetizing enzymes [42]; and reduced hepatic cholesterol concentration due to higher excretion of bile acids via feces, an effect which is probably mediated by an upregulation of the enzymes of bile acid synthesis [43, 44]. It is debated whether different levels of amino acids or 
specified pea peptides are responsible for these lipidlowering effects. Further studies are necessary to isolate the compound responsible for this effect on lipids blood level in diabetic dogs.

In addition to the possible effects intrinsic to pea and barley compounds making them functional foods, there is still the possibility that the lipid-lowering effect of pea and barley is associated to the diet's glycemic index. A recent metabolomic study with obese humans found differential regulation of certain amino acids and phospholipids depending on the diet's glycemic index [46], which could contribute to explain the lipid-lowering effects attributed to low-glycemic index diet on diabetic or hyperlipidemic humans reported previously [47, 48]. It was not measured in our study, but we have already shown that a pea and barley-based diet generate lower glycemic variables in diabetic dogs when compared to a maizebased diet [29]. Additionally, Adolphe et al. [49] pointed that pea has lower glycemic index compared to others starch sources as rice in dogs.

Thus, since peas and barley appear to minimize triglyceridemia and cholesterolemia in diabetic dogs, we believe they should be considered functional foods to dogs with endocrinopathies. Although, it is still a subject of controversy which components of these ingredients are responsible for their effects on lipid metabolism.

\section{Particularities and limitations}

First, an important factor in this research is the isolation of the effect of the diet on blood lipid concentration, because lipid measurements were performed in stable diabetic dogs since the amount of insulin administered was kept constant. Insulin is known to act on several metabolic pathways, including lipid metabolism and there are evidences that high blood triglycerides concentration is associated with insulin resistance [14, 19]. We did not find previous studies on the influence of insulin type in blood lipid concentration, thus all dogs in this study received NPH-type insulin to homogenize factors influencing the lipid metabolism. In addition, there was no variation at animals' body weight. This is important for studies on hyperlipidemia, due to association between high BCS and increases in concentration of triglycerides and cholesterol [50]. Only one dog had BCS higher than ideal (6/9). That excess of adipose tissue probably was not sufficient to cause significant metabolic changes and that dog keept the same BCS (6/9) during all study period.

Second, the methodology chosen to evaluate effect of diet on hyperlipidemia of diabetic dogs was: plasmatic triglycerides and cholesterol concentration measurement by a curve during $10 \mathrm{~h}$, every 2 hours. Some studies that evaluated dietary effects on blood triglycerides and cholesterol concentration used only fasting blood samples to measure these lipid's concentrations [22, 23], but it was observed that fasting triglyceride concentrations do not predict the highest postprandial triglyceridemia in healthy dogs $[31,51]$. Higher differences at plasmatic triglycerides concentrations at different times than fasting was observed in our data and in other studies that evaluated triglyceridemia and cholesterolemia of diabetic dogs by the similar methods to ours [21]. Moreover, in our study, fasting cholesterolemia did not show significant difference between diets, but all other times of curve did. Elliot et al. [31] considered these findings relevant to diabetic dogs because they are fed and given exogenous insulin therapy every $12 \mathrm{~h}$.

Although 12 animals represent a small sample size, based on previous research this study included the similar number of diabetic dogs evaluated for dietary modifications under a crossover design as other studies [2123, 29]. All the animals were spontaneous diabetic dogs and were included after a rigorous selection, considering even the owners commitment to following the protocol. Therefore, we were able to keep the animals under a strict diet, avoiding differences in food intake which could have interfered in lipid metabolism. We did not find another published research that compared isonutrients diets focusing on lipids concentration in diabetic dogs. Also, despite the lipid-lowering effect of peas and barley already being reported in other species, this is the first study to assess it in diabetic dogs.

In our data, we found a high variations (expressed as standard deviation) of the triglycerides concentration. It was observed in other published studies [52], including with diabetic dogs [21]. De Marco et al. (2017) [52] found a range of triglycerides concentration: 350 to $4356 \mathrm{mg} / \mathrm{dL}$. The cited authors did not explain this high variation and we have no explanation as to why values vary so much between individuals. However, we believe this is due to different individual responses related to physiological absence of insulin and the individual changes that occur with other hormones such as leptin and inflammatory markers in diabetic dogs [53, 54], which need to be further studied in veterinary medicine.

An important limitation is that we cannot distinguish whether the beneficial hypolipidemic effect was due to the association of pea and barley or if they have these effects in isolation. Not all the dietary lipid classes were measured, so we cannot reject the possibility of alternative modulation by other means than pea and barley. In this context, another limitation is the fact that $\mathrm{Ba}$ and PB are commercial diets, which made it difficult for us to access the amount included of all the ingredients in each formulation. This also diminishes our ability to assess whether the inclusion of rice in the Ba diet had any influence on the results, because it was expected that the less fat diet, that also has peas and barley in its composition, would generate even lower blood lipids 
concentrations. Likewise, the diets were formulated with different fat sources and the differences in fatty acid profile could impact the lipid metabolism [55]. Probably in a further study the evaluation of all the lipid classes could clarify also this aspect.

The results of the present study suggest a hypocholesterolemic and hypotriglyceridemic effect by the association of pea and barley in diabetic dog's diets. Our results expand the alternatives for nutritional treatment of diabetic dogs and hyperlipidemic dogs, including the possibility of an increase in the amount of dietary fat, which may be an interesting alternative for more selective dogs or for patients with a tendency to lose weight when receiving high-fiber and low-fat diets [21].

Furthermore, dogs may serve as models for human medicine due to metabolomic similarities between diabetic dogs and type-1 human diabetes mellitus [56]. The study of diabetic dogs offers better standardization of diet and treatment while experimenting on individuals with naturally acquired diabetes mellitus, instead of induced diabetes, as is commonly seen. As a result, we believe in the potential these ingredients have for positively affecting human health as well.

\section{Conclusions}

The results obtained from this group of 12 animals under the experimental design conducted, support the claim that peas and barley included in the diet of diabetics dogs can minimize the plasmatic concentration of triglycerides and cholesterol better than maize-based diets and in a similar way to low-fat diet.

\section{Methods}

\section{Animals}

The animals used in this research were selected from the routine practice of the veterinary hospital of the School of Veterinary Medicine and Animal Science of the University of São Paulo as our previous study [29]. In which the medical records of 368 diabetic dogs were analyzed and 18 animals were selected according to the following exclusion criteria (intact female dogs; dogs younger than 1 year old; diagnosis of concomitant diseases; body condition score (BCS) lower than 4 or higher than 6 on a scale [57] of 1 to 9). In the current study, we added the exclusion criteria: treatment with hypolipidemic drug and/or omega-3 polyunsaturated fatty acid for less than 6 months. Sixteen diabetic dogs were included in the study, but four were excluded (one due to personal difficulties of the owner in conducting the experimental protocol, and the other three animals did not accept food in the veterinary hospital environment). Thus, 12 dogs with spontaneous DM and hyperlipidaemia historic were included in this study (Table 1). From diagnosis to start of study, for these 12 dogs the duration of DM ranged from 150 to 1034 days. All animals received Neutral Protamine Hagedorn (NPH) insulin. After the study, all animals were kept in its usual environment home with their owners.

The minimum number of animals, to achieve $80 \%$ of power calculation, was performed by glycemic values from Teshima et al. [30]. This sample size was calculated using statistical program Action ${ }^{\circ}$ to previous research project [29] and resulted in 10 diabetic dogs.

\section{Diets and experimental design}

Dogs entered the experimental protocol after they were considered DM stabilized: at least 45 days without changes in insulin dosage due to absent manifestations of polyuria and polydipsia and blood glucose levels ranging from 5.0 to $16.7 \mathrm{mMol} / \mathrm{L}$ (90 to $300 \mathrm{mg} / \mathrm{dL}$ ) [58]. During this stabilization period, all dogs had been eating the same basal $(\mathrm{Ba})$ commercial dry extruded diet recommended for obese $\operatorname{dogs}^{1}$ (Table 3). After being considered stable, all animals received $\mathrm{Ba}$ diet for additional 60 days. Then, all animals were randomized to receive for 60 days two other diets (PB and $\mathrm{Mi}$ ), in a crossover manner, via a draw of the possible PB-Mi or Mi-PB sequences (Fig. 3). PB is a commercial diet recommended for diabetic dogs ${ }^{2}$ with pea and barley as exclusive starch source. Mi is an experimental diet produced as isonutrient diet in relation to PB diet (Table 3), with the maize as single starch source. Animals were fed in their homes by their owner twice-a-day following NPH insulin administration, with an exact 12-h interval between meals. Insulin dose was not changed over the experimental protocol. Initial caloric requirement was estimated by maintenance formula $\left[397 \mathrm{~kJ} \quad \mathrm{x} \quad \mathrm{BW}^{0.75} \quad(\mathrm{BW}=\right.$ body weight in $\mathrm{kg}$ )] [32]. To guarantee that the study was double-blinded, owners received diets only identified with the letters $\mathrm{A}$ and $\mathrm{B}$, and the researchers responsible for the analysis of the results and for providing the diet to the owners were unaware of the meaning of this identification letters. During experimental protocol, dogs were evaluated every 3 weeks at veterinary hospital (body weight, BCS, blood glucose concentration, and owners were asked about insulin and dietary management, and occurrence of DM manifestation). At each re-evaluation, diet was supplied to owners in enough amount for the dogs to show no change in weight (lesser than $5 \%$ ).

At the end of the 60 days consuming each of the three diets $(\mathrm{Ba}, \mathrm{A}$ and $\mathrm{B})$, the diabetic dogs returned to the veterinary hospital in the morning post 12 -h fasting conditions for plasmatic triglycerides and cholesterol curves. A blood sample was collected before feeding (fasting sample, time 0; t0). After this collection, dogs were fed,

\footnotetext{
${ }^{1}$ Premier Nutrição Clínica Obesidade Cães

${ }^{2}$ Premier Nutrição Clínica Diabetes Cães
} 


\begin{tabular}{|c|c|c|}
\hline At least 45 days & 60 days & All animals 60 days each diet \\
\hline $\begin{array}{c}\text { Stabilization period } \\
\text { Basal diet }\end{array}$ & Basal diet period & $\begin{array}{c}\text { Randomized to PB-Mi or Mi-PB sequence diet } \\
\text { (cross-over; double blind) }\end{array}$
\end{tabular}

Fig. 3 Schematic representation of study design. PB = pea and barley diet; $\mathrm{Mi}=$ maize diet

received the regular dose of insulin, and new blood samples were collected at $2(\mathrm{t} 2), 4(\mathrm{t} 4), 6(\mathrm{t} 6), 8(\mathrm{t} 8)$ and $10 \mathrm{~h}$ (t10) after feeding.

\section{Laboratory analysis}

Blood samples were collected in tubes with fluoride EDTA. Plasma was separated after centrifugation at 3500 rpm for $5 \mathrm{~min}$ and kept frozen at $-20^{\circ} \mathrm{C}$ until analysis. Plasmatic triglycerides concentrations were analyzed by the glycerol phosphate method and plasmatic cholesterol concentration by the enzimatic oxydase/peroxidase method, both using a commercial kit. ${ }^{3}$ Information about diet analyses methods were described previously [29].

\section{Calculations and statistical analysis}

In order to compare the effects of each dietary treatment on lipidemia, the $10 \mathrm{~h}$ triglycerides and cholesterol curves of the 12 dogs were combined and averaged. Consequently the mean triglycerides and cholesterol value for each time point ( $\mathrm{t} 0, \mathrm{t} 2, \mathrm{t} 4, \mathrm{t} 6, \mathrm{t} 8$ and $\mathrm{t} 10)$ and the mean values of fasting, mean, maximum, minimum and fluctuation of triglycerides and cholesterol were calculated between all dogs for each dietary treatment.

Fasting triglyceridemia and cholesterolemia were considered the plasmatic concentration at time to (immediately before feeding). Mean triglycerides and cholesterol were defined as the average of mean of each time point at 10 -h curves values, for each dietary treatment. The maximum and minimum triglycerides and cholesterol values were defined respectively as the mean of the highest and lowest values obtained for each 10-h curves. The difference between maximum and minimum values was defined by subtracting the highest and lowest values of each curve and calculating the average of these differences. The triglycerides and cholesterol increment was calculated by normalizing measurements by subtracting t0 values for each animal. The area under the triglycerides (AUTC) and cholesterol (AUCC) curves and the area under the increment curve (AUTIC and AUCIC) were calculated via numerical integration using the trapezoidal method.

Statistical analyses and numerical integration using the trapezoidal method were performed in a statistical software. $^{4}$ Initially, Bartlett test was applied to verify the

\footnotetext{
${ }^{3}$ Biosystem S.A., Barcelona, Spain

${ }^{4} \mathrm{R}$ Core Team. R: A Language and Environment for Statistical

Computing; R Foundation for Statistical Computing, 2016.
}

homogeneity of variances for triglycerides and cholesterol variables, and body weight after 60 days receiving each diet. Significant variation in all time points of the triglycerides curve, mean triglycerides, average of minimum triglycerides and AUTC, were assessed using Friedman's test and posthoc multiple comparisons test. One factor Anova was conducted on all cholesterol variables (fasting, t2, t4, t6, t8 and t10 curve, mean, maximum, minimum, difference between maximum and minimum, AUCC and AUCIC), to maximum triglycerides, difference between maximum and minimum triglycerides, AUTIC and body weight, due to these variables showing homogeneous variance; followed by a post-hoc Tukey test. For all tests, the $\alpha$ value established for significant results was 0.05 ( $p$ value $\leq 0.05$ ).

\section{Abbreviations}

AUCC: Area under the cholesterol curve; AUCIC: Area under the triglycerides increment curve; AUTC: Area under the triglycerides curve; AUTIC: Area under the triglycerides increment curve; Ba: Basal diet; BCS: Body condition score; BHA: Butylated hydroxyanisole; BW: Body weight; DM: Diabetes mellitus; Mi: Maize based-diet; NPH: Neutral protamine Hagedorn; NRC: Nutrient requirements council; PB: Pea and barley based diet

\section{Acknowledgements \\ We would like to thank the staff of the School of Veterinary Medicine and Animal Science for all their support, specially DVM Denise Maria Nunes Simões and DVM Khadine Kazue Kanayama for helping in diabetic dogs selection; and Grandfood Industria e Comercio LTDA (Premier pet) for supported the study and produced diets. We would also like to thank Alinne Santana-Pereira for the help with the English translation and text revision.}

\section{Authors' contributions}

FAT was responsible for planning the study, selecting and treating animals, conducting the analysis, writing and editing the manuscript. DPM was responsible for conducting the analysis, selecting and treating animals, compiling the data. JTJ and CFFP were responsible for planning the study and manufacturing the diets. MRQ was responsible for data analysis. MAB was responsible for planning study and reviewing the manuscript. All authors have read and approved the manuscript.

\section{Funding}

São Paulo Research Foundation (FAPESP) supported scholarship. Grandfood Industria e Comercio LTDA (Premier pet) participated producing diets and study design. FAPESP and Premier pet had no role in the analysis of results.

\section{Availability of data and materials}

The datasets used and/or analysed during the current study are available from the corresponding author on reasonable request.

\section{Ethics approval and consent to participate}

The present study was conducted with the approval of the Committee of Ethics in Animal Use of the School of Veterinary Medicine and Animal Science of the University of São Paulo, under protocol 1691050214, and all procedures were performed with the dog owners' written consent. Authors ensured that our manuscript conforms to the 'ARRIVE Guidelines for Reporting Animal Research' summarized at www.nc3rs.org.uk. 


\section{Consent for publication}

All dog owners wrote and signed the consent form.

\section{Competing interests}

JJT and CFFP are employed in Grandfood Industria e Comercio LTDA

(Premier pet). Premier pet had no role in the analysis of results, and participated at study design and producing diets.

\section{Author details}

'School of Veterinary Medicine and Animal Science, University of São Paulo, São Paulo/Pirassununga, Av. Prof. Orlando Marques de Paiva, 87 - Butantã, São Paulo 05508-010, Brazil. ${ }^{2}$ Grandfood Industria e Comercio LTDA, km 204, Dourado, São Paulo 13590-000, Brazil. ${ }^{3}$ Department of Animal Nutrition and Production, School of Veterinary Medicine and Animal Science, São Paulo University, Av. Duque de Caxias Norte, 255, Pirassununga, SP, Brazil.

Received: 26 July 2019 Accepted: 25 December 2019

Published online: 03 January 2020

\section{References}

1. Cook AK, Breitschwerdt EB, Levine JF, Bunch SE, Linn LO. Risk factors associated with acute pancreatitis in dogs: 101 cases (1985-1990). J Am Vet Med Assoc. 1993;203:673-9.

2. Hess RS, Saunders HM, Van Winkle TJ, Shofer FS, Washabau RJ. Clinical, clinicopathologic, radiographic, and ultrasonographic abnormalities in dogs with fatal acute pancreatitis: 70 cases (1986-1995). J Am Vet Med Assoc. 1998:213:665-70

3. Xenoulis PG, Levinski MD, Suchodolski JS, Steiner JM. Serum triglyceride concentrations in miniature schnauzers with and without a history of probable pancreatitis. J Vet Intern Med. 2011;25:20-5.

4. Kutsunai M, Kanemoto H, Fukushima K, Fujino $Y$, Ohno K, Tsujimoto $H$. The association between gall bladder mucoceles and hyperlipidaemia in dogs: a retrospective case control study. Vet J. 2014;199:76-9. https://doi.org/10. 1016/j.tvjl.2013.10.019.

5. Sottiaux J. Atherosclerosis in a dog with diabetes mellitus. J Small Anim Pract. 1999;40:581-4. https://doi.org/10.1111/j.1748-5827.1999.tb03027.x.

6. Mahley RW, Innerarity TL, Weisgraber KH, Fry DL. Canine hyperlipoproteinemia and atherosclerosis. Accumulation of lipid by aortic medial cells in vivo and in vitro. Am J Pathol. 1977;87:205-25

7. Liu SK, Tilley LP, Tappe JP, Fox PR. Clinical and pathologic findings in dogs with atherosclerosis: 21 cases (1970-1983). J Am Vet Med Assoc. 1986;189: 227-32.

8. Kagawa Y, Hirayama K, Uchida E, Izumisawa Y, Yamaguchi M, Kotani T, et al. Systemic atherosclerosis in dogs: Histopathological and immunohistochemical studies of atherosclerotic lesions. J Comp Pathol. 1998:118:195-206. https://doi.org/10.1016/S0021-9975(05)80126-4.

9. Hess RS, Kass PH, Van Winkle TJ. Association between diabetes mellitus, hypothyroidism or Hyperadrenocorticism, and atherosclerosis in dogs. J Vet Intern Med. 2003;17:489-94.

10. Crispin SM. Ocular manifestations of Hyperlipoproteinemia. J Small Anim Pract. 1993;34:500-6. https://doi.org/10.1016/0002-9394(70)90890-1.

11. Bodkin K. Seizures Associated with Hyperlipoproteinemia in A Miniature Schnauzer. Canine Pract. 1992:17:11-5 isi:A1992HC78500002.

12. Ford RB. Idiopathic Hyperchylomicronemia in Miniature Schnauzers. J Small Anim Pract. 1993:34:488-92 isi:A1993ME52400003.

13. Xenoulis PG, Suchodolski IS, Levinski MD, Steiner JM. Serum liver enzyme activities in healthy miniature schnauzers with and without hypertriglyceridemia. J Am Vet Med Assoc. 2008;232:63-7. https://doi.org/10. 2460/javma.232.1.63.

14. Xenoulis PG, Levinski MD, Suchodolski JS, Steiner JM. Association of hypertriglyceridemia with insulin resistance in healthy miniature schnauzers. J Am Vet Med Assoc. 2011;238:1011-6. https://doi.org/10 2460/javma.238.8.1011

15. Smith RE, Granick JL, Stauthammer CD, Polzin DJ, Heinrich DA, Furrow E. Clinical consequences of hypertriglyceridemia-associated proteinuria in miniature schnauzers. J Vet Intern Med. 2017:31:1740-8.

16. Furrow E, Jaeger JQ, Parker VJ, Hinchcliff KW, Johnson SE, Murdoch SJ, et al. Proteinuria and lipoprotein lipase activity in miniature schnauzer dogs with and without hypertriglyceridemia. Vet J. 2016;212:83-9.

17. Xenoulis PG, Steiner JM. Canine hyperlipidaemia. J Small Anim Pract. 2015; 56:595-605.
18. Barrie J, Watson TDG, Stear MJ, Nash AS. Plasma cholesterol and lipoprotein concentrations in the dog: the effects of age, breed, gender and endocrine disease. J Small Anim Pract. 1993;34:507-12. https://doi.org/10.1111/j.17485827.1993.tb03523x

19. Wilson DE, Chan IF, Elstad NL, Peric-Golia L, Hejazi J, Albu DS, et al. Apolipoprotein E-containing lipoproteins and lipoprotein remnants in experimental canine diabetes. Diabetes. 1986;35:933-42. https://doi.org/10. 2337/diab.35.8.933.

20. Brada Z, Tobiska J. Heterogeneity of the haemoglobin of the black rat Rattus rattus. Folia Biol (Praha). 1967;13:200-3.

21. Fleeman LM, Rand JS, Markwell PJ. Lack of advantage of high-fibre, moderate-carbohydrate diets in dogs with stabilised diabetes. J Small Anim Pract. 2009:50:604-14. https://doi.org/10.1111/j.1748-5827.2009.00817.x.

22. Graham PA, Maskell IE, Rawlings JM, Nash AS, Markwell PJ. Influence of a high fibre diet on glycaemic control and quality of life in dogs with diabetes mellitus. J Small Anim Pract. 2002;43:67-73. https://doi.org/10.1111/ j.1748-5827.2002.tb00031.x

23. Nelson RW, Duesberg CA, Ford SL, Feldman EC, Davenport DJ, Kiernan C, et al. Effect of dietary insoluble fiber on control of glycemia in dogs with naturally acquired diabetes mellitus. J Am Vet Med Assoc. 1998;212:380-6.

24. Kimmel SE, Michel KE, Hess RS, Ward CR. Effects of insoluble and soluble dietary fiber on glycemic control in dogs with naturally occurring insulindependent diabetes mellitus. J Am Vet Med Assoc. 2000;216:1076-81. https://doi.org/10.2460/javma.2000.216.1076

25. Nelson RW, Ihle SL, Lewis LD, Salisbury SK, Miller T, Bergdall V, et al. Effects of dietary fiber supplementation on glycemic control in dogs with alloxaninduced diabetes mellitus. Am J Vet Res. 1991;52:2060-6.

26. Hoenig M, Laflamme D, Klaser DA, Singer MJ, Ferguson DC. Glucose tolerance and lipid profiles in dogs fed different fiber diets. Vet Ther. 2001;2:160-9.

27. Sandri M, Sgorlon S, Conte G, Serra A, Dal Monego S, Stefanon B. Substitution of a commercial diet with raw meat complemented with vegetable foods containing chickpeas or peas affects faecal microbiome in healthy dogs. Ital J Anim Sci. 2019;18:1205-14

28. Domingues L, Murakami F, Zattoni D, Kaelle G, de Oliveira S, Félix A. Effect of potato on kibble characteristics and diet digestibility and palatability to adult dogs and puppies. Ital J Anim Sci. 2019;18:292-300.

29. Teixeira FA, Machado DP, Jeremias JT, Queiroz MR, Pontieri CFF, Brunetto MA. Effects of pea with barley and less-processed maize on glycaemic control in diabetic dogs. Br J Nutr. 2018;120:777-86. https://doi.org/10.1017/ s000711451800171x

30. Teshima E, Brunetto MA, Gomes MOS, Jeremias JT, Palumbo GR, Carciofi AC Starch influence on glycemic control of diabetic dogs. In: 12th Congress of the European Society of Veterinary and Comparative Nutrition. Vienna: European Societty of Veterinary and Comparative Nutrition; 2008. p. 45.

31. Elliott KF, Rand JS, Fleeman LM, Morton JM, Litster AL, Biourge VC, et al. A diet lower in digestible carbohydrate results in lower postprandial glucose concentrations compared with a traditional canine diabetes diet and an adult maintenance diet in healthy dogs. Res Vet Sci. 2012;93:288-95. https:// doi.org/10.1016/j.rvsc.2011.07.032

32. NRC. Nutrient Requirements of Dogs and Cats. 1st ed. Washington, D.C: National Academy Press; 2006

33. Campbell KL, Czarnecki-Maulden GL, Schaeffer DJ. Effects of animal and soy fats and proteins in the diet on fatty acid concentrations in the serum and skin of dogs. Am J Vet Res. 1995;56:1465-9.

34. Musco N, Calabrò S, Tudisco R, Grossi M, Addi L, Moniello G, et al. Diet effect on short- and long-term glycaemic response in adult healthy cats. Vet tal. 2017;53:141-5. https://doi.org/10.12834Netlt.57.166.3.

35. Hewson-Hughes AK, Gilham MS, Upton S, Colyer A, Butterwick R, Miller AT. The effect of dietary starch level on postprandial glucose and insulin concentrations in cats and dogs. Br J Nutr. 2011;106:S105-9.

36. Parks EJ, Hellerstein MK. Carbohydrate-induced hypertriacylglycerolemia: historical perspective and review of biological mechanisms. Am J Clin Nutr. 2000;71:412-33

37. Skottová N, Krecman V, Walterová D, Ulrichová J, Kosina P, Simánek V. Effect of silymarin on serum cholesterol levels in rats. Acta Univ Palacki Olomuc Fac Med. 1998:141:87-9.

38. Lia A, Hallmans G, Sandberg AS, Sundberg B, Aman P, Andersson H. Oat $\beta$ glucan increases bile acid excretion and a fiber-rich barley fraction increases cholesterol excretion in ileostomy subjects. Am J Clin Nutr. 1995;62:1245-51.

39. Sima P. Vannucci L, Vetvicka V. ß-glucans and cholesterol (Review). Int J Mol Med. 2018;41:1799-808. 
40. Li J, Kaneko T, Qin LQ, Wang J, Wang Y, Sato A. Long-term effects of high dietary fiber intake on glucose tolerance and lipid metabolism in GK rats: comparison among barley, rice, and cornstarch. Metabolism. 2003;52:1206-10.

41. Talati R, Baker WL, Pabilonia MS, White CM, Coleman Cl. The effects of barley-derived soluble fiber on serum lipids. Ann Fam Med. 2009;7:157-63.

42. Rigamonti E, Parolini C, Marchesi M, Diani E, Brambilla S, Sirtori CR, et al. Hypolipidemic effect of dietary pea proteins: Impact on genes regulating hepatic lipid metabolism. Mol Nutr Food Res. 2010;54:1.

43. Spielmann J, Stangl Gl, Eder K. Dietary pea protein stimulates bile acid excretion and lowers hepatic cholesterol concentration in rats. J Anim Physiol Anim Nutr (Berl). 2008;92:683-93.

44. Martins JM, Riottot M, de Abreu MC, Lança MJ, Viegas-Crespo AM, Almeida $J A$, et al. Dietary raw peas (Pisum sativum L.) reduce plasma total and LDL cholesterol and hepatic esterified cholesterol in intact and ileorectal anastomosed pigs fed cholesterol-rich diets. J Nutr. 2004;134:3305-12.

45. Dubois C, Cara L, Armand M, Borel P, Portugal H, Pauli AM, et al. Effects of pea and soybean fibre on postprandial lipaemia and lipoproteins in healthy adults. Eur J Clin Nutr. 1993;47:508-20.

46. Hernández-Alonso P, Giardina S, Cañueto D, Salas-Salvadó J, Cañellas N, Bulló M. Changes in Plasma Metabolite Concentrations after a LowGlycemic Index Diet Intervention. Mol Nutr Food Res. 2018;63:1700975. https://doi.org/10.1002/mnfr.201700975.

47. Jenkins DJA, Wolever TMS, Kalmusky J, Guidici S, Giordano C, Patten R, et al. Low-glycemic index diet in hyperlipidemia: use of traditional starchy foods. Am J Clin Nutr. 1987;46:66-71.

48. Järvi $A E$, Karlström BE, Granfeldt $Y E$, Björck IE, Asp NG, Vessby BO. Improved glycemic control and lipid profile and normalized fibrinolytic activity on a low-glycemic index diet in type 2 diabetic patients. Diabetes Care. 1999;22: 10-8.

49. Adolphe JL, Drew MD, Huang Q, Silver TI, Weber LP. Postprandial impairment of flow-mediated dilation and elevated methylglyoxal after simple but not complex carbohydrate consumption in dogs. Nutr Res. 2012; 32:278-84. https://doi.org/10.1016/j.nutres.2012.03.002.

50. Jeusette IC, Lhoest ET, Istasse LP, Diez MO. Influence of obesity on plasma lipid and lipoprotein concentrations in dogs. Am J Vet Res. 2005;66:81.

51. Elliott KF, Rand JS, Fleeman LM, Morton JM, Markwell PJ. Use of a meal challenge test to estimate peak postprandial triglyceride concentrations in dogs. Am J Vet Res. 2011;72:161-8. https://doi.org/10.2460/ajvr.72.2.161.

52. De Marco V, Noronha KSM, Casado TC, Nakandakare ER, Florio JC, Santos EZ, et al. Therapy of canine hyperlipidemia with Bezafibrate. J Vet Intern Med. 2017:31:717-22.

53. O'Neill S, Drobatz K, Satyaraj E, Hess R. Evaluation of cytokines and hormones in dogs before and after treatment of diabetic ketoacidosis and in uncomplicated diabetes mellitus. Vet Immunol Immunopathol. 2012;148: 276-83.

54. Kim AY, Kim HS, Kang JH, Yang MP. Serum adipokine concentrations in dogs with diabetes mellitus: a pilot study. J Vet Sci. 2015;16:333-40.

55. de Godoy MRC, MCLeod KR, Harmon DL. Influence of feeding a fish oilcontaining diet to mature, overweight dogs: effects on lipid metabolites, postprandial glycaemia and body weight. J Anim Physiol Anim Nutr (Berl). 2018;102:e155-65.

56. O'Kell AL, Garrett TJ, Wasserfall C, Atkinson MA. Untargeted metabolomic analysis in naturally occurring canine diabetes mellitus identifies similarities to human type 1 diabetes. Sci Rep. 2017;7:9467. https://doi.org/10.1038/ s41598-017-09908-5.

57. Laflamme DP. Development and validation of a body condition score system for dogs. Canine Pract. 1997;22:10-5.

58. Behrend E, Holford A, Lathan P, Rucinsky R, Schulman R. 2018 AAHA diabetes management guidelines for dogs and cats. J Am Anim Hosp Assoc. 2018;54:1-21. https://doi.org/10.5326/JAAHA-MS-6822.

\section{Publisher's Note}

Springer Nature remains neutral with regard to jurisdictional claims in published maps and institutional affiliations.

Ready to submit your research? Choose BMC and benefit from:

- fast, convenient online submission

- thorough peer review by experienced researchers in your field

- rapid publication on acceptance

- support for research data, including large and complex data types

- gold Open Access which fosters wider collaboration and increased citations

- maximum visibility for your research: over $100 \mathrm{M}$ website views per year

At BMC, research is always in progress.

Learn more biomedcentral.com/submissions 